\title{
The Symposium and the Role of Literature for Epistemic Development
}

\begin{abstract}
By Susanna Saracco*
Plato's dialogues are not invented to begin and end in the mind of their author. The cognitive construction of the Platonic dialogues is not meant to be a bidimensional one, given by the thought of their author and the written words that he uses to express it, but it is a tridimensional building, whose volume is given by the epistemic contributions of Plato's readers. Plato's dialogues can be read as rational stimulations of their reader, who is required to complete them with her thinking. This higher-order pedagogy is at the base of my interpretation of the use of literature in the "Symposium" as means to stimulate the engagement of Plato's readers. Cooperating actively with the text they become aware of their rational power. This knowledge of themselves is subsequent to a phase of epistemic discomfort, in which they recognize that the cognitive horizon which they thought to be the place for undoubtable truths was the source of controversial content.
\end{abstract}

\section{The Platonic Use of Literature}

In this paper I will consider the use of literature in the Symposium as an instrument for the epistemic development of Plato's reader. The scope of this work is not that of presenting the arguments about my interpretation of the Platonic dialogues as rational stimulations of the reader. Here I will assume that the Platonic written work is constructed by its author to promote the intellectual development of the reader. This assumption allows me to focus the present work on the presentation of one of the means used by Plato to stimulate the intellect of his reader: literature.

In the next two sections of this paper I will take into consideration the literature used by Plato in the Symposium, to show how the Platonic dialogues can be actively interrogated by their reader and how this cooperation between the written words and their readers can have as its outcome the rational evolution of people who are at the beginning of the process of intellectual development. Since I will try to reproduce faithfully the engagement with the Platonic text of someone who has not yet reached a high degree of epistemic sophistication, the display of that engagement will present very basic reasoning. Nonetheless, this attempt adds something to the understanding of the quoted Platonic passages in the sense that it shows how they can be interrogated and completed by a reader who is required to cooperate actively with the written words. At the same time, my examples of the reasoning of someone who is at the beginning of her epistemic growth, do not add anything to the comprehension of the excerpts quoted, if we want to see this comprehension as rigidly fixed in a definitive

${ }^{*}$ Postdoctoral Researcher. 
cognitive horizon in which there can be only one correct interpretation of Plato's words.

I think that this is a too narrow understanding of Plato's thought but, as I said, the complete argumentation about Plato's dialogues as rational stimulations, is not the scope of this work. Nonetheless, it is necessary that here I sketch briefly my theory about the Platonic texts as means of epistemic development, so to contextualize better the subject of this research, focused on one way in which the rational stimulation can take place, via the use of literature.

I want to start presenting my idea that Plato's text requires the completion by its reader. This implies a cooperation between the reader and the text. This kind of collaboration can take place whenever a text is read and, more particularly, whenever a text is read critically. What differentiates the Platonic dialogues is that their criticism is required by their creator: Plato wants his readers to critically engage with his words, completing them with their rational activity.

Plato's texts display a higher-order pedagogy: they are not didactic, bidimensional, texts which are the result of the ideas of their author and the words that he uses to express his thought. Plato requires the intellectual activity of his readers, which is the third dimension which adds rational volume to Plato's work.

The tridimensional nature of Plato's work is confirmed by his words: in the Phaedrus ${ }^{1}$ he explicitly connects the process of learning with what is inside us, which makes us remember, recollect, a wisdom that is merely reminded by the written words. The written words can be only reminders, they cannot make us remember something that is inside us, because they depend on signs that "belong to others." 2 These Platonic thoughts make us realize that his written words were not conceived as the final destination of knowledge, but rather as a stimulus to reach that destination, which is internal to us. The Platonic words are only a reminder of the necessity of looking for knowledge where the answers to the dialogical questions come from: inside us, in the organ which remembers, which is, for Plato, the soul and its main component, reason. Plato's dialogues do not end in the flat form shaped by the thinking of the author and the written words, the reminders, that he has chosen to convey it. Plato's writing is enriched by the volume represented by the myriads of rational memories of his readers.

The tridimensionality of Plato's work is suggested by J. F. Mattéi. In commenting on the Republic, Mattéi draws a distinction between two ways of interacting with Plato's text. He says:

1. Plato, Phaedrus, trans. Alexander Nehamas and Paul Woodruff, in Plato: Complete Works, ed. J. M. Cooper (Indianapolis: Hackett, 1997), 275 a-b.

2. Ibid., 275 a. 
The existence of myth allows us to distinguish two sorts of spectacle lovers. The first are the crowd and the sophists who unreservedly dedicate themselves to the sensible beauty of colors, forms and voices. As Socrates puts it to Glaucon: "those who love to watch" (philotheamones) and "those who love to listen" (philēkooi; Rep., $475 \mathrm{~d} 2$ ) remain the prisoners of appearances even if they show an unconscious desire for a higher kind of knowledge. In front of them, "those who love to know"the philosophers-are in search of the luminous theater of truth beyond the shadow play. Like the pure souls released from their bodies and contemplating the vast plain of Truth, and like the initiate in Eros' mysteries contemplating the boundless ocean of the Beautiful, "the genuine philosophers are those who are in love with the spectacle of the truth" (Rep., 475 e). ${ }^{3}$

Here Mattéi highlights that the spectacle created by Plato is not something to be passively watched, it is not what we would call a bidimensional show. Rather, it has to be appreciated in a tridimensional way, as that rational stimulation which has to be criticized because it is not the final destination for the intellectual growth of its reader. If we confuse a means of rational growth with the ultimate goal of this process, we are condemned to live in an epistemic realm in which the shadows are for us the reality. But if we interpret the Platonic message as tridimensional, as a message which has to be enriched with the critical contributions of its readers, we allow the words of Plato to perform the real show they were invented for, the show in which the absolute protagonist is human reason.

I have explained so far, in a very basic way, my idea that Plato's dialogues require the active intellectual participation of the readers. A text of this kind promotes the cognitive growth of the reader, calling for a cooperation between the reader and the written words. Cooperation offers a crucial contribution to our rational progress, as it is emphasized by modern pedagogists: Vygotsky thinks that cooperation is the only pedagogical method which allows learners to work with people who know more than they do. ${ }^{4}$ When we, as learners, are challenged by someone who knows more than we do, this stimulation makes us gradually leave what we are able to do to move in the direction of a successive phase of rational development.

This exposition to the reasoning of people who have reached a high level of intellectual development is, according to Kohlberg, ${ }^{5}$ well portrayed by the Socratic questioning, in which the interlocutors of the philosopher are challenged by a more refined reasoning than theirs. For Kohlberg, if teachers used Socratic

3. Jean-François Mattéi, The Theatre of Myth in Plato, in Platonic Writings/Platonic Readings, ed. Charles L. Griswold (New York: Routledge, 1988).

4. Vygotsky, Thought and Language, trans. newly revised Alex Kozulin (Cambridge, MA: MIT Press, 1986), 189.

5. Kohlberg, The Philosophy of Moral Development: Moral Stages and the Idea of Justice (New York: Harper \& Row Pub., 1981), 27. 
questioning, they would stimulate their "students in such a way as to arouse disagreement and uncertainty as to what is right"6 and this would "stimulate stage growth." 7 The involvement in a dialectical exchange with someone intellectually more sophisticated than we are, opens up a cognitive horizon characterized by a controversiality that has to be analyzed using our critical skills. According to Kohlberg the dialogical interaction contributes to the rational development of the person insofar as "the approach differs from indoctrinative approaches because it tries to move student's thinking in a direction that is natural for the student rather than moving the student in the direction of accepting the teacher's moral assumptions. It avoids preaching or didacticism linked to teacher's authority."8

This antithesis between education based upon a dialectical exchange and indoctrination is also stressed by Freire who states that when a dialogue takes place between a student and the teacher "the teacher is no longer merely theone-who- teaches, but one who is himself taught in a dialogue with the students, who in turn while being taught also teaches."9 The student, who is not the mere passive receptor of a content, discovers herself as author of the content: she discovers her "creative power"10 and her rational abilities. This result is obtained using dialectical interaction as a way to engage the students in critical thinking. ${ }^{11}$

As Kohlberg highlighted, dialogical interaction is at odds with indoctrination. In a dialogue, the one who knows less is guided by the one who knows more, but this guidance is not an imposition of the point of view of the individual who is epistemically more sophisticated. On the contrary, the one who knows more leads the one who knows less to the development of her own direction of thinking. This is what Plato's dialogues do: they intellectually stimulate the reader so that she engages with the text in a critical way, completing it with her original and creative thinking.

Nonetheless, Plato establishes clear boundaries to define what it is knowledge for him: the highest point of intellectual development is reached when we are able to abandon completely the empirical and reach the purely intelligible. The presence of these boundaries does not mean that the contribution of Plato's reader to the completion of his text is not autonomous: the reader of Plato's works has the choice to use her rational capabilities, sharpened through the texts of the philosopher, to criticize Plato's conception of knowledge, abandoning in this way Plato's philosophical system.
6. Ibid.
7. Ibid.
8. Ibid., 28. My emphasis.
9. Freire, Pedagogy of the Oppressed (New York: Continuum, 1970), 80.
10. Ibid., 73.
11. Ibid., 83. 
Alternatively, the individual contributions of Plato's readers can take place within the concept of Platonic knowledge, moulded into the shape their intellect suggests.

I have chosen this second option and I have utilized modern pedagogy to convey my interpretation of the Platonic dialogues as means of rational progress based upon cooperation. A good example of this process is given by the Socratic questioning which makes emerge the controversiality of subjects which were not recognized as problematic. The acknowledgment of this controversiality reveals an epistemic evolution which is the outcome of a collaboration with someone who possesses a degree of intellectual sophistication higher than ours and is able to stimulate our active engagement with the topics taken into consideration.

I have described the basics of my idea of the Platonic written texts as rational stimulations which promote the intellectual evolution of the readers. I will not explain here the complete justification of this interpretation of the Platonic text. But it is important to assume that Plato's dialogues are epistemic games, intellectual constructions built by the philosopher to increase the knowledge of his readers. The scope of the dialogues is the promotion of the intellectual development of people who are still in need of the reminder of the written word, as that stimulation necessary to remember the truth which is inside them..$^{12}$ These people, who are starting their epistemic evolution, have to interact rationally with the words written by Plato. In the Symposium the epistemic games are played using literature which is familiar to Plato's contemporaries. This recognizability of the literary component of the epistemic game engages the reader, making the cooperation between the written text and the reader start. The Symposium is the dialogue which offers the best chance to analyze examples of epistemic games based upon literature, since in this dialogue we see a conspicuous presence of the "most successful strategies of literary communication in contemporary Greek culture ... above all from Attic tragedy and the epic poems of Homer and Hesiod, both of them genres politically institutionalized at Athens as the predominant literary forms at that time."13

12. The meaning of this statement can be better understood in the context of the illustration of the whole epistemic evolution of the individual for Plato, from its beginning till its end, in which the person has no necessity of the reminder of the written words. But the explanation of this part of my theory is not the scope of this paper.

13. Glenn W. Most, Plato's Exoteric Myths, in Plato and Myth, ed. Catherine Collobert, Pierre Destrée and Francisco J. Gonzales (Leiden and Boston: Brill, 2012), 22. Most speaks about the fact that "Plato had to study, master, deploy and then invert the most successful strategies of literary communication in contemporary Greek culture ..." (p. 22. My emphasis) but I do not think that all the literary tools taken from Plato's culture had to be inverted: some of the literary mechanisms used at the time of the 
I am not going to deepen the notion of epistemic game or that of recognizability. Nonetheless, I want to specify that, when I connect the recognizability of the epistemic games played in the Symposium with the familiarity that Plato's contemporaries had with the literary material cited in the dialogue, I am not stating that it is impossible for a reader to engage with Plato's text without the contribution of quotations taken from a familiar author. I am only saying that familiar literary sources offer to people who are at the beginning of their epistemic evolution a good occasion to grow intellectually, interacting with the text to contribute to its completion.

Before seeing some examples of this interaction with the text, I want to stress that the literary Platonic allusions of the Symposium can engage also the contemporary reader because their content is not too complex and thus it does not require the familiarity with the literature of the ancient Greek culture to be recognizable. Nevertheless, at Plato's time, the literary epistemic stimulations reported in the Symposium were likely to be intellectually more powerful because Plato's contemporaries had more familiarity with the practice of using during the symposia allusions from shared texts, as those that we can read in Plato's dialogue. This knowledge created, to the readers of Plato's time, an occasion to engage with the text of the Symposium not only at a simple level, reflecting upon the possibility that the use of literature in the context of the description of a symposium, could be only a means for Plato to reconstruct a typical situation of his time, but also at a deeper level, investigating whether this reconstruction was made to be interrogated so to discover a further shade of its meaning. These two modes of completing the Platonic text of the Symposium are also possible for the contemporary reader, but only once she is informed about the way in which the symposia took place at Plato's time. In any case, the reader of the Symposium can complete this text with contributions which do not necessarily require their contextualization in the symposia known at Plato's time.

\section{The Symposium and the Literary Epistemic Games}

I want to repeat briefly the core element of Mattéi's view, because it gives us the chance to reflect upon the very beginning of the Symposium. We have seen that Mattéi pointed to the necessity of overcoming intellectually the appearance of the spectacle constructed by Plato's words in order to grasp its real meaning: if we flatten Plato's message against a bidimensional perspective, given by the author's thought and the texts which are the outcome of it, we miss the crucial, third, dimension of his work, the individual contributions of the

philosopher could be useful as they were as means to arise questions in the mind of the readers, promoting in this way their intellectual growth. 
readers. This failure leads us to grasp only the "shadow play"14 of Plato's message, which is where the Symposium starts: since Socrates is going to the house of a good-looking man he has to pay attention to his appearance, so he bathes and wears fancy sandals to look at his best. ${ }^{15}$ Kalos, beauty, in this context certainly does not define an intellectual beauty but then, at the end of the epistemic journey of the dialogue, the "luminous theatre of truth"16 is evoked through the beautiful things which can be used as "rising stairs"17 to reach the Beautiful itself. This time, for sure, kalos is not associated with a superficial idea of physical beauty but with an intellectual beauty which represents for Plato the peak of cognitive development.

This level of rational evolution is achieved thanks to the epistemic stimulation of the Platonic games which, as we have seen, are based upon the use of recognizable, familiar, means to attract the attention of people who are starting their rational growth. As Mattéi has just reminded us, these people will have to overcome the surface of the Platonic words to be able to grasp their deeper significance as rational stimuli. This necessity is strongly stressed by Alcibiades who, describing Socrates' method of inquiry, emphasizes how its importance can be fully grasped only when we overcome the appearance of the Socratic arguments: ${ }^{18}$

Come to think of it, I should have mentioned this much earlier: even his ideas and arguments are just like those hollow statues of Silenus. If you were to listen to his arguments, at first they'd strike you as totally ridiculous; they're clothed in words as coarse as the hides worn by the most vulgar satyrs. He's always going on about pack asses, or blacksmiths, or cobblers, or tanners; he's always making the same tired old points in the same tired old words. If you are foolish, or simply unfamiliar with him, you'd find it impossible not to laugh at his arguments. But if you see them when they open up like the statues, if you go behind their surface, you'll realize that no other arguments make any sense. They're truly worthy of a god, bursting with figures of virtue inside. They're of great-no, of the greatest-importance for anyone who wants to become a truly good man. ${ }^{19}$

The following analysis of the Symposium has the purpose of examining the epistemic games played in the dialogue. This investigation has the goal to overcome the surface of the meaning of the Platonic words, to emphasize their real scope, the intellectual stimulation of the readers. At the beginning of the

14. Mattéi, The Theatre of Myth in Plato, 79. My emphasis.

15. Plato, Symposium, trans. Alexander Nehamas and Paul Woodruff, in Plato: Complete Works, ed. J. M. Cooper (Indianapolis: Hackett, 1997), 174 a-b.

16. Mattéi, The Theatre of Myth in Plato, 79. My emphasis.

17. Plato, Symposium, $211 \mathrm{c}$.

18. The elenchus as epistemic game is not the subject of this paper.

19. Plato, Symposium, 221 d-222 a. My emphasis. 
Symposium, Plato describes the encounter of Socrates and Aristodemus. Socrates invites Aristodemus to accompany him at Agathon's dinner, even though Agathon has not invited Aristodemus:

"Come with me, then," Socrates said, "and we shall prove the proverb wrong; the truth is, "Good men go uninvited to Goodman's feast."' Even Homer himself, when you think about it, did not much like this proverb; he only disregarded it, he violated it. Agamemnon, of course, is one of his great warriors, while he describes Menelaus as a "limp spearmen." And yet, when Agamemnon offers a sacrifice and gives a feast, Homer has the weak Menelaus arrive uninvited at his superior's table..$^{20}$

Here Homer is cited in relation to the violation of a proverb: Menelaus, even if he is weak, and thus inferior to Agamemnon, goes uninvited to the feast of the superior, which should be appropriate only for an uninvited person who is as good as the host to join. The readers engage with the text through the words of a recognizable author. The Homeric criticism of a proverb can stimulate a stream of thoughts in the readers: they can reflect upon the differences between an authority, in this case Homer as cultural authority, and a common person and they can ask themselves if only an authority or also a common person can criticize what is widely accepted. They can also take into consideration the reasons why the proverb was criticized and they can realize that there were no good reasons to believe in the proverb while the reasons to behave differently from what the proverb suggested are better. All these thoughts are originated by a recognizable element, in this case Homer's words about the participation in a feast. They are the literary component on which the epistemic game is centred. I have reconstructed some basic lines of reasoning which can be provoked by this literary epistemic game. These lines of reasoning contribute to the rational evolution of someone who is at the beginning of this process.

Immediately after having occasioned this thinking using Homer, Plato quotes again the same author:

"'Let's go,' he said. We'll think about what to say 'as we proceed the two of us along the way'."21

Here Socrates is exhorting Aristodemus to follow him: even if Agathon has not invited him at his dinner, they can think about a justification while they are going there. In this line there is an allusion to Iliad X.224, "when two go together, one has an idea before the other."22 This literary epistemic game is

20. Ibid., 174 b-c.

21. Ibid., $174 \mathrm{~d}$. My emphasis.

22. Ibid. 
more fine-grained than the one we have seen before: in the previous excerpt the proverb subject of Homeric violation was explicitly cited, while here the reader has to connect autonomously the text of the philosopher with the Homeric works, realizing that the point that the quote in the Symposium and the excerpt from the Iliad have in common is interaction: two can obtain a result, an idea is the outcome of the interaction of two people. In this case the epistemic game is focused on a literary allusion from which can start a reflection about the importance of being exposed to different points of view. These thoughts can make the reader realize that epistemic progression is not the consequence of univocal acceptance or criticism, which is at the base of the Platonic choice of transmitting his knowledge in a dialogical form. One outcome of the previous literary epistemic game was a reflection upon the possibility of criticizing what is widely accepted. This second epistemic game, more complex than the first one, leads the reader to consider the way in which this criticism can be developed: the reader can think about the importance of the cooperation with another person who offers her point of view to sharpen our thinking. This cooperation is portrayed in the Platonic dialogues and, as I said in the first section of this work, is required by them. For Plato, as we have seen commenting on the Phaedrus, his written words cannot be the end of the rational evolution of the reader but they are a means for her cognitive progress. Plato's readers have to cooperate with the text written by the philosopher, completing it with their contributions. In this way Plato's written work is used appropriately, as a tool of epistemic growth.

After Agathon's guests have decided to try not to drink too much Eryximachus speaks:

Let me begin by citing Euripides' Melanippe: "Not mine the tale." What I am about to tell belongs to Phaedrus here, who is deeply indignant on this issue, and often complains to me about it. ${ }^{23}$

Eryximachus is connecting Phaedrus' suggestion of speaking in praise of Love and his complaints about the fact that no one has done that before, with a literary source, to stress that this proposal was not his own idea but someone else's. Here the epistemic game is not centred on a criticism of Euripides or Eryximachus, who merely report someone else's ideas, but is rather focused on the connection between the start of the discussion about Love and literature: as Euripides tells a content which is not his own one, similarly Eryximachus is reporting Phaedrus' proposal that someone praises Love. The ironical shade which can be attributed to the quotation from Euripides has the effect of pointing at the elements stressed by the irony: the author of the tale and the tale itself. Thus, this citation of Euripides has the important function

23. Ibid., 177 a. 
of making us focus on the occasion which originated the discussions whose content we are going to know. It is plausible to think that Plato chose this epistemic game to stress from the very beginning of the Symposium the significant role that literature would have played in it, as the base on which the epistemic games of this dialogue are constructed.

Phaedrus' praise of Love begins with the statement that it is

one of the most ancient gods, ${ }^{24}$ and the proof of his great age is this: the parents of Love have no place in poetry or legend. According to Hesiod,

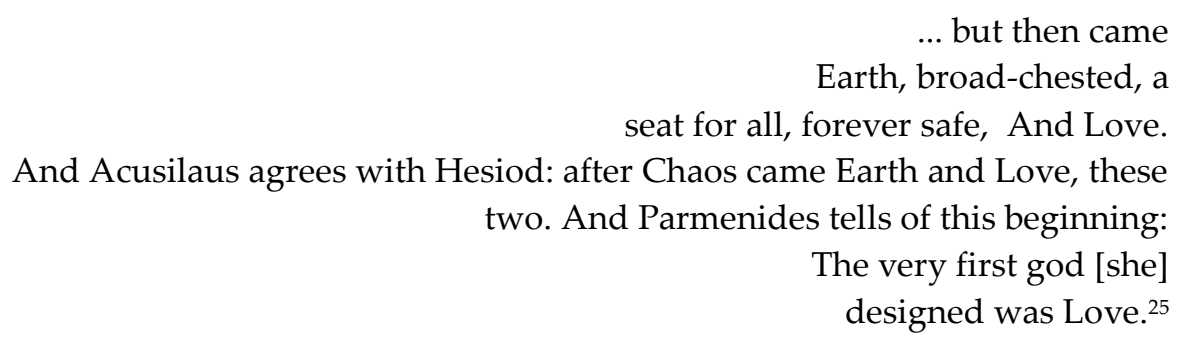

Poetry is here explicitly cited as negative proof ${ }^{26}$ of the longevity of Love: since there is no literary trace of the genealogy of Love, it has to be very old. This kind of evidence may seem to belong to the realm of the intelligible but if we reflect more on the nature of this proof we realize that it is a mere statement of facts which has no non-narrative counterproof. This understanding can make us think that poetry has been relegated to a realm of belief intended as passive acceptance. On the contrary, also in this case, literature has been used to contribute to the rational evolution of the reader. In fact, in this excerpt, the literary epistemic game stimulates our intellect, making us reflect upon the nature of a good rational proof, together with what can be the criteria which define its reliability.

Phaedrus' speech on Love goes on with its characterization as cause of courage:

And as for leaving the boy behind, or not coming to his aid in danger-why, no one is so base that the true Love could not inspire him with courage, and make him as brave as if he'd been born a hero. When Homer says a god "breathes might" into some of the heroes, this is really Love's gift to every lover. ${ }^{27}$

In these lines we can see that the use of literature is limited to a couple of words. This can make us wonder whether the epistemic game can be based upon such a minimal presence of literature. The epistemic games that we have

24. Agathon in Symposium $195 \mathrm{~b}$ seems to disagree.

25. Plato, Symposium, 178 a-c.

26. Ibid., $178 \mathrm{~b}$.

27. Ibid., 179 a-b. 
taken into consideration so far are contributing to the development of our rational ability, pointing to one important feature of the speech, which stimulates our thinking. This goal can be attained with the use of a very brief literary quotation. In the excerpt above, the literary element, which is the recognizable element of the epistemic game, corresponds to Homer's words about courage. They stimulate us to reflect upon the possible connection between the courage of some of the Homeric heroes and Love. Following this line of reasoning, we can think about cases in which Love is not accompanied by courage and we can evaluate if these examples could be considered as valid reasons against Phaedrus' point.

Phaedrus, after having related Love to courage, speaks about Achilles and Patroclus:

He chose to die for Patroclus, and more than that, he did it for a man whose life was already over. The gods were highly delighted at this, of course, and gave him special honor, because he made so much of his lover. Aeschylus talks nonsense when he claims Achilles was the lover; he was more beautiful than Patroclus, more beautiful than all the heroes, and still beardless. Besides he was much younger, as Homer says. ${ }^{28}$

The epistemic game, after having been focused on the possibility of Love as cause of courage, presents us, through the relationship between Achilles and Patroclus, one of the instantiations of this possibility. It is offered us the chance to continue our rational evolution, evaluating the likelihood that the subject of Love is more courageous than his object. Moreover, we can consider whether the examples presented in literature can validly ground the connection between Love and courage.

Phaedrus' discourse is followed by Pausanias'. Pausanias explains that there are two kinds of Love, Common Aphrodite's Love and Love of Heavenly Aphrodite:

I'll tell you: it is the common, vulgar lover, who loves the body rather than the soul, the man whose love is bound to be inconstant, since what he loves is itself mutable and unstable. The moment the body is no longer in bloom, "he flies off and away," his promises and vows in tatters behind him. How different from this is a man who loves the right sort of character, and who remains its lover for life, attached as he is to something that is permanent. ${ }^{29}$

Here, as we have noticed analyzing Phaedrus' words, the literary allusion is composed by few Homeric words ${ }^{30}$ but, as it was emphasized commenting on

28. Ibid., 179 e-180 a.

29. Ibid., 182 d-183 e.

30. Ibid., Iliad, II. 71. 
that case, the epistemic game can be based on a very brief literary element, because it serves the scope to attract the rational attention of the readers on a precise point. In this case, we are lead to reflect upon a consequence of a bad way of loving: if you are in love with a body rather than with a soul, when the body "is no longer in bloom"31 your affection rapidly fades away. This line of reasoning, centred on the negative consequences of an unstable way of loving, is originated by the epistemic game and can have as its outcome the evaluation of the occurrence of this kind of consequences also when the person is in love with a soul. This reflection contributes to our intellectual development, which can go on with the investigation of the reasons necessary to reject or support Pausanias' characterization of two kinds of Love.

Aristophanes speaks after Pausanias about how Human Nature was at its beginning:

Now here is why there were three kinds, and why they were as I described them: the male kind was originally an offspring of the sun, the female of the earth, and the one that combined both genders was an offspring of the moon, because the moon shares in both. They were spherical, and so was their motion, because they were like their parents in the sky. In strength and power, therefore, they were terrible, and they had great ambitions. They made an attempt on the gods, and Homer's story about Ephialtes and Otus ${ }^{32}$ was originally about them: how they tried to make an ascent to heaven so as to attack the gods. ${ }^{33}$

In these lines, as in the excerpt in which Phaedrus described the longevity of Love, what literature is telling us has no counterproof: no one can have witnessed events which took place such a long time ago. Nonetheless, as we have emphasized, this does not mean that in this case literature belongs to a realm of belief which imposes the passive acceptance of the point of view which is reporting. On the contrary, as we have seen, literature contributes to the intellectual evolution of the reader, creating the occasion to reflect on the reasons to believe in something and on the characteristics that these reasons should have to be considered valid.

Aristophanes' discourse goes on pointing at the motivations which make us choose to share our life with someone else:

These are the people who finish out their lives together and still cannot say what it is they want from one another. No one would think it is the intimacy of sex-that mere sex is the reason each lover takes so great and deep a joy in being with the other. It's obvious that the soul of every lover longs for something else; his soul cannot say what it is, but like an oracle it has a sense of what it wants, and like an

31. Ibid., 183 e.

32. Ibid., Iliad V.385, Odyssey XI.305 ff.

33. Ibid., 190 a-c. 
oracle it hides behind a riddle. Suppose two lovers are lying together and Hephaestus stands over them with his mending tools, asking, "What is it you human beings really want from each other?"34

Here Plato mentions the metal-working god described in the Odyssey: ${ }^{35}$ when he knows that Ares and Aphrodite laid together in his house, he forges bonds which it is not possible to break or loose so that the lovers would be bound fast where they were. We have seen epistemic games based upon very brief literary quotations. Here the epistemic game is based upon only one literary allusion: the reference to the mythological character Hephaestus. Again, this does not mean that the epistemic game is not well grounded. In fact, this Homeric reference is sufficient to stimulate rationally Plato's readers because it can make them reflect upon what two people "really want from each other:"36 is this topic examined by Hephaestus because Love is not sufficient to explain the relationship between two people? Do Love and Homer's character have something in common? If their nature has some similarity does this mean that Love is mythological in the sense of being at odds with reason? Is Love completely or partially extraneous to the rational realm? All these questions arise from the literary epistemic game and contribute to the rational development of Plato's reader.

Aristophanes' speech is followed by Agathon's enquiry into the delicate nature of Love:

It takes a poet as good as Homer to show how delicate the god is. For Homer says that Mischief is a god and that she is delicate-well, that her feet are delicate, anyway! He says:

... hers are

delicate feet: not on the ground Does she draw nigh; she walks instead upon the heads of men

A lovely proof, I think, to show how delicate she is: she doesn't walk on anything hard; she walks only on what is soft. We shall use the same proof about Love, then, to show that he is delicate. For he walks not on earth, not even on people's skulls, which are really not soft at all, but in the softest of all the things that are, there he walks, there he has his home. For he makes his home in the characters, in the souls, of gods and men-and not even in every soul that comes along: when he encounters a soul with a harsh character, he turns away; but when he finds a soft and gentle character, he settles down in it. ${ }^{37}$

34. Ibid., 192 c-d.

35. Ibid., Odyssey VIII.266 ff.

36. Ibid., $192 \mathrm{~d}$.

37. Ibid., 195 c-e. 
The lines of Homer about the "heads of men,"38 quoted in this Platonic excerpt, stimulate in the reader a reflection upon the delicacy of Love, which prevents Love from walking on people's heads, because they are "really not soft at all." 39 Here the literary epistemic game makes the reader grow intellectually, encouraging her reflection on the connection between one of the characteristics of Love and the place where it could be found.

Delicacy, according to Agathon's words, is not the only feature of Love:

And as for manly bravery "Not even Ares can stand up to" Love! For Ares has no hold on Love, but Love does on Ares-love of Aphrodite, so runs the tale. ${ }^{40}$

In these lines there is an allusion to a fragment of Sophocles in which it is stated that "even Ares cannot withstand Necessity,"41 together with a reference to the part of the Odyssey in which Ares is caught in bed with Aphrodite, wife of Hephaestus. ${ }^{42}$ These literary elements are at the base of an epistemic game which points to a connection between the god of war, Ares, and Love. This epistemic game stimulates the reader to take into consideration the possibility that the power of Love is superior to that of war. The reader can evaluate whether this is a chance related to any kind of Love or whether it can occur only when Love is particularly strong. The rational evolution of Plato's reader can go on with a more fine-grained reflection, centred on the reasons of the modification of the fragment of Sophocles. The reader can think that this change has been made to suggest an association of Love with Necessity. This association can have the purpose of pointing to the ability of Love to render necessary the actions which are exemplified by the relationship between Ares and Aphrodite.

Agathon, after having spoken about the bravery of Love, mentions sophia, wisdom, as one of the features of Love:

Now I have spoken about the god's justice, moderation and bravery; his wisdom remains. I must try not to leave out anything that can be said on this. In the first place- to honor our profession as Eryximachus did his-the god is so skilled a poet that he can make others into poets: once Love touches him, anyone becomes a poet,

\footnotetext{
38. Ibid., $195 \mathrm{~d}$.

39. Ibid., $195 \mathrm{e}$.

40. Ibid., 196 c-d.

41. Ibid., Fragment 234b Dindorf.

42. Ibid., Odyssey viii 266-366.
} 
This, we may fittingly observe, testifies that Love is a good poet, good, in sum, at every kind of artistic production. For you can't give to another what you don't have yourself, and you can't teach what you don't know. ${ }^{43}$

Here the literary quote which grounds the epistemic game is taken from Euripides. ${ }^{44}$ These words contribute to our intellectual growth, making us reflect upon the relationship between culture and Love: how can Love be the cause of culture? Is culture intended as expression of rationality and thus Love, as cause of it, is, to a certain extent, rational? Is this rationality what Plato had in mind when he wrote about the sophia, wisdom, of Love? Does Love give rationality to poets? Does Love inspire poets? And if inspiration is an offer of Love, has something rational in its nature because Love is rational or both Love and inspiration do not share in rationality? Or Love has a rational nature but inspiration is not a form a Love? If this last case were true what is it that inspires Agathon who, after having spoken about the sophia of Love, is "suddenly stuck by a need to say something in poetic meter?"45

Socrates' comments follow Agathon's intervention in the conversation about Love:

And, you see, the speech reminded me of Gorgias, so that I actually experienced what Homer describes: I was afraid that Agathon would end by sending the Gorgian head, awesome at speaking in a speech, against my speech, and this would turn me to stone by striking me dumb. 46

Agathon's vehement way of speaking about Love is the subject of Socrates' irony, based upon the reference to Gorgia's rhetoric style. This style is sketched using the words of Homer about the sight of a Gorgian's head, which would have as its consequence, the transformation into a stone of the person who saw it. This quotation from Homer is at the base of an epistemic game which promotes the rational development of its reader, making her think about the power of words. The ironic tone of the passage creates also the occasion to reflect upon the possibility that a vehement style is not necessarily conveying an epistemically valuable message.

The flaws in what we say are stressed by this Socratic remark:

It was in ignorance that I agreed to take part in this. So "the tongue" promised and "the mind" did not. ${ }^{47}$

43. Ibid., 196 d-e.

44. Ibid., Euripides, Stheneboea (frg. 666 Nauck).

45. Ibid., 197 c.

46. Ibid., $198 \mathrm{c}$.

47. Ibid., 199 a. 
Socrates emphasizes the difference between what "the tongue" 48 and "the mind" $49 \mathrm{do}$, through an allusion to Euripides. ${ }^{50}$ The epistemic game centred on this allusion, stimulates the reflection on the fallibility of our words, when they do not follow our mind. We can associate this observation with the comparison, mentioned in the previous excerpt, between Agathon's words about Love and Gorgias' dialectic style: if even Socrates' words can be pronounced without being adequately rationally informed, this could be the case also for Agathon's ardent speech. Moreover, since the reference utilized by Socrates is taken from a tragedy, it creates the occasion to take into consideration the possibility that the separation between tongue and mind is not a premise of good outcomes.

Towards the end of the dialogue it is suggested to follow Eryximachus ${ }^{51}$ guidance:

Whatever you say. Ours to obey you, "For a medical mind is worth a million others." Please prescribe what you think fit. ${ }^{52}$

This epistemic game is grounded in a quote from Homer, ${ }^{53}$ which can be taken literally, as confirmation of Eryximachus' authoritative voice or also ironically. In the latter case, the intellectual growth of the reader is promoted by the realization that even a doctor, who is socially considered as an authority, can be the subject of criticism. Thus, here the function of irony would be that of creating a stimulus for a reflection on social conventions. In this way, Plato's readers have the chance to notice that these conventions are not necessarily supported by valid reasons. If the outcome of this thought is that Eryximachus is not superior to the others because of his profession but his proposal is in any case valid, it can be taken into consideration the eventuality that good arguments are not always related to what is socially evaluated as good.

Following Eryximachus' advice, Alcibiades is the next person to speak. He decides to tell his audience about how he proposed to Socrates to become his lover so to take advantage of his teachings to become better. This is Socrates's reply to Alcibiades' offer:

48. Ibid.

49. Ibid.

50. Ibid., Euripides, Hyppolitus 612.

51. Eryximachus's main intervention in $185 \mathrm{~d}-189$ a presents peculiarities which make it the subject for an independent work from this.

52. Plato, Symposium, 214 b.

53. Ibid., Iliad xi.514. 
Dear Alcibiades, if you are right in what you say about me, you are already more accomplished than what you think. If I really have in me the power to make you a better man, then you can see in me a beauty that is really beyond description and makes your own remarkable good looks pale in comparison. But, then, is this a fair exchange that you propose? You seem to me to want more than your proper share: you offer me the merest appearance of beauty, and in return you want the thing itself, "gold in exchange for bronze." 54

The Homeric words ${ }^{55}$ which are at the base of the epistemic game, point to the difference between what gold and bronze are. The occasion for the development of the intellectual capacities of Plato's readers is given by what Socrates intends as bronze: a young, good-looking lover, who is even more accomplished than what he is aware of. This is indeed what most people will consider gold. This alternative perspective can be the origin of reflections about the existence of opinions which differ from the common ones. The consequent analysis of what could be the reasons which support this uncommon way of thinking can start from Socrates' definition of gold, as something which cannot be the "appearance of beauty"56 but it has to be the beauty itself. These Socratic statements have the power to cause a stream of thoughts about what beauty itself is and how it can be grasped which leads the reader to the knowledge of the purely intelligible, which is for Plato the maximum peak which can be achieved by human intellection.

\section{Being out of Place to Know Yourself}

The previous section starts and ends with an exhortation to go beyond the appearances. This goal can be attained through the rational stimulations which are the Platonic epistemic games. These games, as we have seen, are characterized by a recognizable element; in the Symposium, this element is literature, which cognitively challenges the readers so that they begin a process of critical evaluation of the text, evolving rationally. A fundamental moment of the epistemic growth of Plato's readers is related to their feeling out of place in the epistemic horizon in which they have previously been certain to find the right answers to their questions.

This sense of rational discomfort has not to be rejected but it has to be cultivated as the positive sign of a cognitive progression which is showing the individual a new perspective to consider what is commonly accepted by the majority. It is necessary that Plato's readers have the strength to make a

54. Ibid., 218 d-e.

55. Ibid., Iliad., vi. 232-36.

56. Ibid., 218 e. 
rational choice which may transform what seemed an undoubtable truth into a controversial statement if they want to evolve epistemically. Plato asks his readers, rational creatures who are fighting for their knowledge, the courage to behave as the soldier Socrates. The deeds of the philosopher, both on the intellectual and on the practical battlefield, are described by Alcibiades in the Symposium:

So much for that! But you should hear what else he did during that same campaign,

The exploit our strong-hearted hero dared to do

One day, at dawn, he started thinking about some problem or other; he just stood outside, trying to figure it out. He could not resolve it, but he wouldn't give up. He simply stood there, glued to the same spot. By midday, many soldiers had seen him, and, quite mystified, they told everyone that Socrates had been standing there all day, thinking about something. ${ }^{57}$

This epistemic game uses the quote from Homer to make us reflect upon the reason why the simple act of staying outside, thinking, has to be considered the brave act of a "strong-hearted hero." 58 Does this action require strength because it is different from what all the others are doing? When Plato chose this quote did he want to highlight how much strength it is necessary to expose yourself to everyone's judgement without the fear of appearing out of place in respect to them?

The beginning of the dialogue seems to provide an affirmative answer to this question: Socrates is gone to the porch of Agathon's neighbours and he stands there, reflecting instead of joining the rest of the group for dinner. This choice of not acting like the majority is described by Agathon as "strange,"59 "atopon,"60 out of place. Choosing to behave differently from the rest of a group requires a certain amount of courage and the description of Socrates' conduct on the battlefield provided by the next quote seems to ground the possibility that the philosopher is fearless:

You should also have seen him at our horrible retreat from Delium. I was there with the cavalry, while Socrates was a foot soldier. The army had already dispersed in all directions, and Socrates was retreating together with Laches. I happened to see them by chance, and the moment I did I started shouting encouragements to them, telling them I was never going to leave their side, and so on. That day I had

57. Ibid., 220 c.

58. Ibid., Odyssey, iv. 242, 271.

59. Ibid., 175 a.

60. Ibid. 
a better opportunity to watch Socrates than I ever had at Potidaea, for, being on horseback, I wasn't in very great danger. Well, it was so easy to see that he was remarkably more collected than Laches. But when I looked again I couldn't get your words, Aristophanes, out of my mind: in the midst of battle he was making his way exactly as he does around town,

... with swagg'ring gait and roving eye

He was observing everything quite calmly, looking out for friendly troops and keeping an eye on the enemy. ${ }^{61}$

Here the epistemic game is centred on a portrait of Socrates. Even intending it only as a caricature, this irony stimulates the intellect of the readers who can ask themselves why Plato decided to ridicule courage through the words of Aristophanes: ${ }^{62}$ did he make this choice because he dislikes courage or because he wants to use irony to offer his readers an example of what can happen when you decide to live according to an uncommon behaviour, represented in the quotation above by the careful calm displayed by Socrates during the battle? This gives Plato's reader the chance to choose to complete the text of the Symposium according to the same criteria of judgment utilized by those who, like Aristophanes, consider Socrates a fanatic or according to the outcomes of a critical reflection of these criteria.

As we have seen so far, Plato is using literary elements to stimulate intellectually his readers. The epistemic games elaborated by Plato offer to the readers the possibility to begin to take into consideration the likelihood of the existence of a cognitive realm different from the familiar one. This alternative cognitive realm is built by their intellectual contributions. Plato's written words create for the readers the occasion to know themselves as thinking creatures. This understanding makes them realize that a passive approach towards knowledge is a misfortune from which they have to learn but that they have not to accept. This seems to be the message of the following literary quotation, the last of the Symposium,

learn your lesson from your own misfortune.63

This is an allusion to Homer, ${ }^{64}$ used by Alcibiades to warn his friends about Socrates' cruelty, which made him reject Alcibiades' offer of Love. This line cannot be considered as having the only purpose of stressing the pains of Love. In fact, it comes immediately after the words that we saw at the beginning

61. Ibid., 221 a-b.

62. Ibid., Aristophanes, Clouds 362.

63. Ibid., 222 b.

64. Ibid., Iliad, xvii.32. 
of the previous section. ${ }^{65}$ They expressed an exhortation which is crucial for the epistemic development of Plato's readers: it is necessary that they overcome the appearance of Socrates' teachings to be able to see that they are infused with Socrates' intellectual bravery, which appears beyond the surface of Socrates' methodology. The readers who are at the beginning of their rational evolution must understand Socrates' lesson of life and they must show his same courage. In this way they will avoid the misfortune of living in a cognitive world of appearances because of the fear of a learning process which requires to give up the security of a familiar intellectual realm.

\section{Bibliography}

Freire. Pedagogy of the Oppressed. New York: Continuum, 1970.

Kohlberg. The Philosophy of Moral Development: Moral Stages and the Idea of Justice. New York: Harper \& Row Pub., 1981.

Mattéi, Jean-François. The Theatre of Myth in Plato, in Platonic Writings/Platonic Readings, edited by Charles L. Griswold. New York: Routledge, 1988.

Most, Glenn W. Plato's Exoteric Myths. In Plato and Myth, edited by Catherine Collobert, Pierre Destrée and Francisco J. Gonzales. Leiden and Boston: Brill, 2012.

Plato. Phaedrus. Translated by Alexander Nehamas and Paul Woodruff. In Plato: Complete Works, edited by J. M. Cooper. Indianapolis: Hackett, 1997.

Plato. Symposium. Translated by Alexander Nehamas and Paul Woodruff. In Plato: Complete Works, edited by J. M. Cooper. Indianapolis: Hackett, 1997.

Vygotsky. Thought and Language. Translation newly revised by Alex Kozulin. Cambridge, MA: MIT Press, 1986.

65. Ibid., 221 d-222 a. 